\title{
Predictive values of ultrasound-based scoring system in morbidly adherent placenta for high risk group
}

\author{
Abd El-Naser Abd El-Gaber Ali ${ }^{1}$, Ahmed AM. Mohammad, \\ Mustafa M. Khodry ${ }^{1}$, Khaled M. Abdallah ${ }^{2}$, Ahmed M. Abbas ${ }^{3 *}$
}

\begin{abstract}
${ }^{1}$ Department of Obstetrics and Gynecology, Faculty of Medicine, South Valley University, Qena, Egypt ${ }^{2}$ Department of Obstetrics and Gynecology, Faculty of Medicine, Al-Azhar University, Assiut, Egypt ${ }^{3}$ Department of Obstetrics and Gynecology, Faculty of Medicine, Assiut University, Assiut, Egypt
\end{abstract}

Received: 21 August 2018

Accepted: 27 September 2018

\section{*Correspondence:}

Dr. Ahmed M. Abbas,

E-mail: bmr90@hotmail.com

Copyright: () the author(s), publisher and licensee Medip Academy. This is an open-access article distributed under the terms of the Creative Commons Attribution Non-Commercial License, which permits unrestricted non-commercial use, distribution, and reproduction in any medium, provided the original work is properly cited.

\section{ABSTRACT}

Background: The objective of the present study was to find out the predictive values of an ultrasound-based scoring system in diagnosis of morbidly adherent placenta (MAP) for high risk group. Obstetrics and Gynecology Department, Faculty of Medicine, South Valley University, Egypt.

Methods: 63 full term pregnant women ( $\geq 37$ weeks of gestation) with high risk of morbidly adherent placenta underwent elective cesarean section. Placental assessment by $2 \mathrm{D}$ ultrasound based on ultrasound scoring system in morbidly adherent placenta, these data were recorded for further comparison with intraoperative data for degree of placental adherence.

Results: Incidence of MAP was 7.93\% (4.76\% had a focal form and 3.17\% had a complete form of accreta). As regarding to scoring system, 82.5 of cases had a low risk $(<5), 9.5 \%$ had a moderate risk $(6-7)$ and $7.93 \%$ had a high risk (8-12) of development of morbidly adherent placenta with p value $<0.0001$. The sensitivity, specificity, positive and negative predictive values of the US scoring system for morbidly adherent placenta were $(92.3 \%, 94.1 \%$, $87.453 \%$ and $98.2 \%$ ) respectively.

Conclusions: Ultrasound based scoring system had a high predictive value (sensitivity, specificity, positive and negative predictive values) in diagnosis of morbidly adherent placenta for pregnant women have any risk factors for developing MAP.

Keywords: Morbidly adherent placenta (MAP), Placenta, Ultrasound based scoring system

\section{INTRODUCTION}

The term morbidly adherent placenta includes a spectrum of variable pathological conditions as placenta (accreta, increta and percreta) that are associated with serious maternal and fetal morbidity and sometimes are associated with maternal and fetal mortalities. ${ }^{1}$

As a result of the notably increased rate of Cesarean deliveries. The incidence of placenta accreta increased from about $0.8 / 1000$ deliveries in 1980 s to $3 / 1000$ deliveries in the early years of this century. ${ }^{2}$ Placenta previa in addition to any uterine surgery represent the main risk factors for morbidly adherent placenta (MAP). ${ }^{1,3,4}$

The risk of MAP increases in the presence of any uterine scars as cesarean delivery or gynecologic surgeries as endometrial curettage, myomectomy (especially if uterine cavity was opened during procedure), and metroplasty (if implantation was on the scarred area), advanced maternal age (>35 years) and increased maternal parity. In presence of one previous cesarean scare (CS) the risk 
increases to $3 \%, 40 \%$ for $3 \mathrm{CS}$ and $67 \%$ for $5 \mathrm{CS} .{ }^{5}$ About one third to one half of all the emergency hysterectomies occur post vaginal delivery or during cesarean delivery are due to adhesive placental disorders. ${ }^{6}$

MAP can be classified as regarding to the depth of infiltration inside the myometrium into:

- Placenta accreta, where there is a direct contact of chorionic villi to myometrium with absence of decidua basalis

- Placenta increta, where chorionic villi invade the myometrium but not reach the serous layer

- Placenta percreta, villi invade the whole thickness of myometrium and reach or extend beyond the serosa layer into the surrounding structures. ${ }^{7}$

Antenatal diagnosis of morbidly adherent placenta and a multidisciplinary team approach to care had the potential in reduction maternal and fetal complications during delivery, including intrapartum hemorrhage, blood transfusion requirement, emergency hysterectomy, intraoperative gastrointestinal and urological injuries, and even maternal mortalities. ${ }^{8-11}$

Prenatal ultrasonography (US) represents the first-line method for diagnosing antepartum placental abnormalities, with high sensitivity and specificity rates reported at $85.7 \%$ and $88.6 \%$, respectively. ${ }^{12}$

Ultrasound assessment (with grayscale in combination with color Doppler imaging) is highly recommended as first-line modality in MAP diagnosis. ${ }^{13,14}$

Features of grayscale u/s suggestive of MAP include:

- Loss of myometrial interface or retroplacental clear space

- $\quad$ Reduced myometrial thickness

- The presence of intra-placental lacunae..$^{15,16}$

After ultrasound assessment, scoring system must integrate the features mentioned before in predicting placental invasion of individual sonographic parameters into a well-defined scoring system.

Previous investigators had proposed a well standardized evaluation of women who are at risk of MAP. ${ }^{17,18}$

This study aimed to find out the predictive values of an ultrasound-based scoring system in diagnosis of morbidly adherent placenta for high risk pregnant women.

\section{METHODS}

This was a prospective observational study conducted on 63 full term pregnant women ( $\geq 37$ weeks of gestation) with high risk of morbidly adherent placenta from those attendants for obstetrics and gynecology department of
Qena university hospital and underwent elective cesarean delivery from June 2017 to May 2018.

\section{Inclusion criteria}

- Presence of any risk factors of morbidly adherent placenta as all type's placenta previa

- Previous Cesarean delivery

- Previous myomectomy

- Previous curettage

- History of rupture uterus

- History of adherent placenta in previous pregnancy previous metroplasty or intrauterine adhesolysis and history of post-abortive or postpartum infection).

A written consent was required from each woman met inclusion criteria and accepted to participate in this study according to the medical ethics committee of south valley university.

Methods: Detailed history taken, full general and obstetric examinations, routine investigations and routine ultrasound assessment for fetal biometrics, aminiotic fluid assessment, placental location and grading, exclusion of fetal malformations. Specific ultrasound assessment of placenta using two-dimensional (2D) grayscale imaging and color Doppler flow mapping was used in this study.

The ultrasound examination was based on determination of the probability for morbidly adherent placenta (Figures 1-5). All ultrasound images were reviewed and scored according to six different criteria:

- The number and size of placental lacunae

- Obliteration of the demarcation between the uterus and the placenta

- Number of previous cesarean deliveries

- Placental location

- Color Doppler assessment of the placental lacunae blood flow

- Placenta bladder and/or hypervascularity of uteroplacental interface. ${ }^{19-21}$

Each criterion was assigned ( 0,1 or 2$)$ points and the sum of the points that had obtained from each criterion yielded the final score.

According to this ultrasound-based scoring system, the patients were classified into 3 groups: (a) low risk group had $\leq 5$ points, (b) moderate risk group had 6-7 points and high-risk group had 8-12 points.

Intra-operative placental assessment; cesarean sections were operated by highly experienced senior obstetrician and multidisciplinary team with preoperative consultation of the blood bank was conducted and six units of cross matched and serology free packed RBCs. 

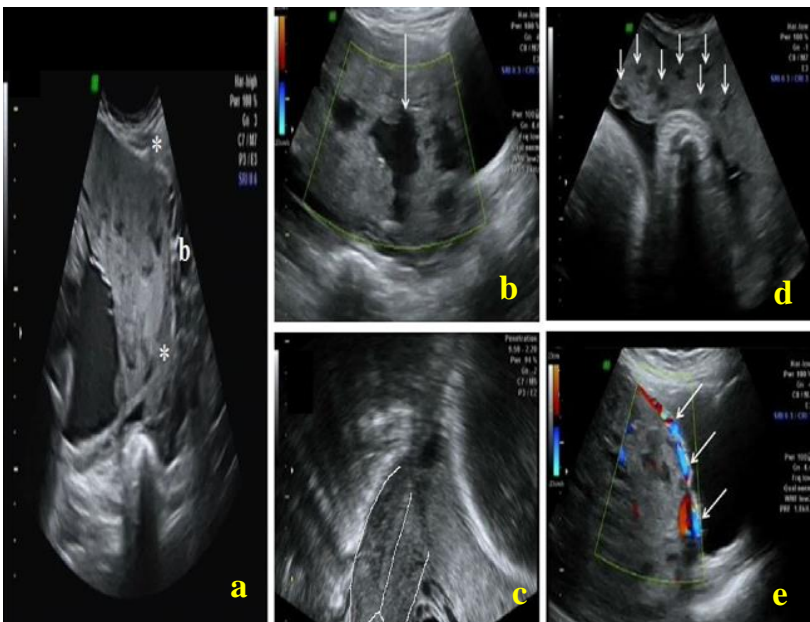

a
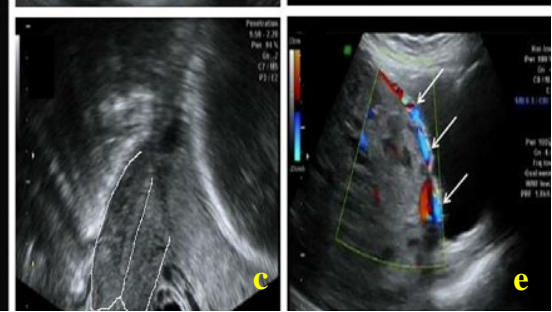

Figure 1: (a) Scoring system for morbidly adherent placenta prediction in a patient with previous 2 cesarean section had ( 2 points); demarcation obliteration (*) between placenta and uterine wall had

( 2 points); (b) the size of Placental lacunae $\geq 2 \mathrm{~cm}$

(arrow, 2 points); (c) placenta previa (outline of cervix, 2 points); (d) the number of placental lacunae equal or more than $2 \mathrm{~cm}$ (arrows, 2 points); (e) finally, the hypervascularity between the placenta and bladder wall as shown by the color Doppler evaluation (arrows, 2 points); the previous collectively points that obtained from each criterion yields the maximum score of 12 points which indicating a high probability of MAP (Tovbin et al).22

Data during surgery included; evaluation the degree of placental invasion wither the placenta was morbidly adherent placenta or not, and in case of MAP we had assessed the degree of adhesion (focal or total adhesion) and the depth of penetration or the degree of imbedding in the uterine wall (accreta, increta and percreta).

\section{Statistical analysis}

Data were statistically analyzed by Microsoft Excel 365, Statistical Package for Social Science (SPSS) Ver. 21 and Minitab statistical software Ver. 17.

Data was expressed as number (\%) or mean \pm standard deviation (SD). Comparison between categorical data performed using Chi square test was used in analysis and comparison among different data. Sensitivity, specificity, positive predictive value (PPV), negative predictive value (NPV) and diagnostic accuracy were the standard diagnostic indices. Significant data considered if $p$ value was $\leq 0.05$ and highly significant if $p$ value $<0.01$.

\section{RESULTS}

Fifty cases $(79.3 \%)$ had a least one previous CS, 4 cases $(6.3 \%)$ had a previous myomectomy, 2 cases $(3.2 \%)$ had a previous endometrial curettage and one case (1.6\%) had a previous metroplasty (Table 1).
Table 1: Patient characteristics.

\begin{tabular}{|ll|}
\hline Characteristic & No. $(\%)$ \\
\hline \multicolumn{1}{|c|}{ Age in years } & \\
\hline $25-35$ & $13(20.64)$ \\
\hline$>35$ & $44(69.84)$ \\
\hline Parity & $6(9.52)$ \\
\hline $0-2$ & \\
\hline $3-5$ & $39(61.90)$ \\
\hline$>5$ & $22(34.92)$ \\
\hline BMI $\left(\mathbf{k g} / \mathbf{m}^{2}\right)$ & $2(3.18)$ \\
\hline$<25$ & \\
\hline $25-29$ & $29(46.04)$ \\
\hline$\geq 30$ & $23(36.50)$ \\
\hline Gestational age in weeks & $11(17.46)$ \\
\hline$\leq 37$ & \\
\hline$>37$ & $27(42.86)$ \\
\hline Previous uterine surgery & $36(57.14)$ \\
\hline Cesarean sections & \\
\hline$\bullet \quad 1$ & \\
\hline$\bullet \quad 2-3$ & $22(34.9)$ \\
\hline$\bullet \quad 24$ & $25(39.6)$ \\
\hline Curretage & $3(4.7)$ \\
\hline Myomectomy & $2(3.2)$ \\
\hline Metroplasty & $4(6.3)$ \\
\hline & $1(1.6)$ \\
\hline
\end{tabular}

As regard to the findings of ultrasound parameters according to the scoring system (anterior position, nonobliterated uteroplacental demarcation, absence of lacunae and increased blood flow in lacunae had highly statistically significant differences with $\mathrm{p}$ value $<0.0001$ (Table 2).

Table 2: The ultrasound parameters according to the scoring system.

\begin{tabular}{|c|c|c|}
\hline Parameters & No. $(\%)$ & P-value \\
\hline \multicolumn{3}{|l|}{ Placental location } \\
\hline Anterior & $51(80.95)$ & \multirow{3}{*}{$\mathrm{P}<0.0002$} \\
\hline Posterior & $8(12.70)$ & \\
\hline Fundal & $4(6.35)$ & \\
\hline \multicolumn{2}{|l|}{ Uteroplacental demarcation } & \multirow{3}{*}{$\mathrm{P}<0.0001$} \\
\hline Obliterated & $11(17.46)$ & \\
\hline Not obliterated & $52(82.54)$ & \\
\hline \multicolumn{2}{|l|}{ Lacunae } & \multirow{3}{*}{$\mathrm{P}<0.0001$} \\
\hline Present & $10(15.87)$ & \\
\hline Absent & $53(84.13)$ & \\
\hline \multicolumn{2}{|l|}{ Doppler assessment } & \multirow[b]{3}{*}{$\mathrm{P}<0.0001$} \\
\hline Blood flow in placental lacunae & $46(73.1)$ & \\
\hline $\begin{array}{l}\text { Hypervascularity of placenta- } \\
\text { bladder and/or uteroplacental } \\
\text { interface }\end{array}$ & $17(26.9)$ & \\
\hline
\end{tabular}

As regarding to scoring system, 52 cases $(82.5 \%)$ had a low risk $(<5), 6$ cases $(9.5 \%)$ had a moderate risk $(6-7)$ and 5 cases $(7.93 \%)$ had a high risk (8-12) of development of morbidly adherent placenta with $\mathrm{p}$ value 
$<0.0001$ (Table 3). Incidence of MAP was $7.93 \%$ (5 cases) with 3 cases $(4.76 \%$ had a focal form of accreta) and 2 cases $(3.17 \%$ had a complete form of accreta).

Logistic regression was used to examine the relationship between US variables found to be significantly associated with MAP on univariable analysis and operative diagnosis of MAP.

All US parameters were found to be significant predictors for MAP (Table 4). The sensitivity, specificity, positive and negative predictive values of the US scoring system for morbidly adherent placenta were $(92.3 \%, 94.1 \%$, $87.4 \%$ and $98.2 \%$ respectively).

Table 3: The US score of the cases.

\begin{tabular}{|c|c|c|}
\hline Total $n=63$ & & \\
\hline Score & No. $(\%)$ & P-value \\
\hline Low $(<5)$ & $52(82.6)$ & \multirow{3}{*}{0.0002} \\
\hline Moderate (6-7) & $6(9.5)$ & \\
\hline High $(8-12)$ & $5(7.9)$ & \\
\hline Mean \pm SD & & $5.9 \pm 1.2$ \\
\hline
\end{tabular}

Table 4: Logistic regression was used to examine the relationship between US variables found to be significantly associated with morbidly adherent placenta on univariable analysis and operative diagnosis of morbidly adherent placenta.

\begin{tabular}{|llll|}
\hline Variables & Odds ratio & $95 \%$ CI & P-value \\
\hline Presence of placental lacunae & 1.89 & $0.89-3.23$ & 0.0001 \\
\hline Blood flow in the placental lacunae & 2.11 & $1.61-2.78$ & 0.0001 \\
\hline Hypervascularity of placenta-bladder interface & 1.56 & $0.72-2.97$ & 0.0001 \\
\hline Anterior placenta & 2.67 & $1.23-3.82$ & 0.0002 \\
\hline Posterior placenta & 1.34 & $0.75-1.77$ & 0.0002 \\
\hline Obliteration of the uteroplacental demarcation & 2.49 & $1.76-4.12$ & 0.0001 \\
\hline
\end{tabular}

$P$ value $<0.0001$ highly significant

\section{DISCUSSION}

Prenatal prediction of morbidly adherent placenta actually big challenge because most cases of MAP are asymptomatic during pregnancy and the prenatal diagnosis can give the multidisciplinary team the time to set delivery plan, which will help in minimizing the surgical complications, decrease of maternal blood loss and decrease the time of intensive care unit admissions. ${ }^{23-}$ 25

In this study we had found the main findings that the ultrasound scoring system was derived from the number of CS, placental position and the placental lacunae characters, obliteration of uteroplacental demarcation and the color Doppler blood flow measures was highly predictive of morbidly adherent placenta, allowing for prenatal and intrapartum special management. In this study the powerful ultrasound criteria for prediction of morbidly adherent placenta were the number of placental lacunae in combination with obliteration of the uteroplacental demarcation and these results agreed with many previous studies reports. ${ }^{26-31}$

The actual pathophysiology of placental lacunae is not Completely clear, in spite of a strong relationship between lacunae spaces and invasion of placental had been explained in many previous studies. ${ }^{32,33}$ There are two retrospective studies had proposed a standardized evaluation of pregnant women carrying risk for development of MAP. ${ }^{17,18}$ Gilboa et al had reported a study of 21 pregnant women with placenta percreta that was identified at surgery and had proposed a scoring system based on the ultrasound findings. ${ }^{17}$ They detected placenta percreta rate about $63.6 \%$, however their scoring system main goal was to detect patients with stage 3 of morbidly adherent placenta and advised for a prophylactic uterine artery catheterization.

Rac et al had created a equation for prediction of placental invasion based on ultrasound parameters which were studied in 88 pregnant women. ${ }^{18}$ In present study the predictive values of the US scoring system for morbidly adherent placenta (sensitivity, specificity, positive and negative predictive values) were $(92.3 \%$, $94.1 \%, 87.453 \%$ and $98.2 \%$ respectively) and these results agreed with what had been reported by Tovbin et al. ${ }^{22}$ Logistic regression was used for examination the relationship between the variables of U/S that had been found to be significantly associated with MAP on univariable analysis and the operative diagnosis of MAP; the OR for MAP was $1.89(95 \% \mathrm{Cl}: 0.89-3.23)$ for the presence of placental lacunae and OR was $2.11(95 \% \mathrm{Cl}$ : 1.61-2.78) for lacunae Doppler blood flow. As regarding to the obliteration of the uteroplacental demarcation, the OR was $2.49(95 \% \mathrm{Cl}: 1.76-4.12)$. As regarding to Hypervascularity of placenta-bladder interface, OR was $1.56(95 \% \mathrm{Cl}: 0.72-2.97)$ and as regarding to placental position, OR for anterior position of placenta was 2.67 (95\% Cl: 1.23-3.82) and for posterior placenta was 1.34 $(95 \% \mathrm{Cl}: 0.75-1.77)$ and these results agreed with what had been reported by Tovbin et al. ${ }^{22}$ 


\section{CONCLUSION}

Ultrasound based scoring system had a high predictive value (sensitivity, specificity, positive and negative predictive values) in diagnosis of morbidly adherent placenta for pregnant women have any risk factors for developing MAP. Non-invasive prenatal diagnosis of MAP can give the multidisciplinary team the time to set the best plan for management of MAP during delivery, that could contribute in minimizing the surgical complications, decline incidence of intrapartum and postpartum hemorrhage and decrease the maternal morbidity, ICU admission and shortening the duration of patient hospital stay. As regarding to the above conclusions, the study recommends using prenatal ultrasonic scoring system as a tool for diagnosis of morbidly adherent placenta in high risk patients.

\section{Funding: No funding sources}

Conflict of interest: None declared

Ethical approval: The study was approved by the Institutional Ethics Committee

\section{REFERENCES}

1. Gielchinsky Y, Rojansky N, Fasouliotis SJ, Ezra Y. Placenta accreta - summary of 10 years: a survey of 310 cases. Placenta. 2002; 23(2):210-4.

2. Publications Committee, Society for Maternal-Fetal Medicine, Belfort MA. Placenta accreta. Am J Obstet Gynecol. 2010; 203(5):430-9.

3. Wu S, Kocherginsky M, Hibbard JU. Abnormal placentation: twenty-year analysis. Am J Obstet Gynecol. 2005;192(5):1458-61.

4. Esh-Broder E, Ariel I, Abas-Bashir N, Bdolah Y, Celnikier DH. Placenta accreta is associated with IVF pregnancies: a retrospective chart review. BJOG. 2011;118(9):1084-9.

5. Kayem G, Deneux-Tharaux C, Sentilhes L,. PACCRETA: clinical situations at high risk of placenta ACCRETA/percreta: impact of diagnostic methods and management on maternal morbidity. Acta Obstet Gynecol Scand. 2013; 92(4):476-82.

6. Leyendecker JR, DuBose M, Hosseinzadeh K, Stone R, Gianini J, Childs DD, et al. MRI of pregnancyrelated issues: abnormal placentation. AJR Am J Roentgenol. 2012;198(2):311-20.

7. Algebally AM, Yousef RR, Badr SS, Al Obeidly A, Szmigielski W, Al Ibrahim AA. The value of ultrasound and magnetic resonance imaging in diagnostics and prediction of morbidity in cases of placenta previa with abnormal placentation. Pol J Radiol. 2014;79:409-716.

8. Wehrum MJ, Buhimschi IA, Salafia C, Thung S, Bahtiyar MO, Werner EF, et al. Accreta complicating complete placenta previa is characterized by reduced systemic levels of vascular endothelial growth factor and by epithelial-tomesenchymal transition of the invasive trophoblast. Am J Obstet Gynecol. 2011; 204(5):411.e1-11.
9. Warshak CR, Ramos GA, Eskander R, Benirschke K, Saenz CC, Kelly TF, Moore TR, Resnik R. Effect of predelivery diagnosis in 99 consecutive cases of placenta accreta. Obstet Gynecol. 2010; 115(1):65-9.

10. Abuhamad A. Morbidly adherent placenta. Semin Perinatol 2013; 37(5):359-64.

11. Eller AG, Porter TF, Soisson P, Silver RM. Optimal management strategies for placenta accreta. BJOG. 2009;116(5):648-54.

12. D'Antonio F, Iacovella C, Palacios-Jaraquemada J, Bruno CH, Manzoli L, Bhide A. Prenatal identification of invasive placentation using magnetic resonance imaging: systematic review and meta-analysis. Ultrasound Obstet Gynecol. 2014;44(1):8-16.

13. Grosvenor A, Silver R, Porter TF, Zempolich K. Optimal management of placenta accreta. Am J Obstet Gynecol. 2006;195(6):S82.

14. Committee on Obstetric Practice. Committee opinion no. 529: placenta accreta. Obstet Gynecol. 2012; 120(1):207-11.

15. Finberg HJ, Williams JW. Placenta accreta: prospective sonographic diagnosis in patients with placenta previa and prior cesarean section. J Ultrasound Med.1992;11(7):333-43.

16. D'Antonio F, Iacovella C, Bhide A. Prenatal identification of invasive placentation using ultrasound: systematic review and meta-analysis. Ultrasound Obstet Gynecol. 2013;42(5):509-17.

17. Gilboa Y, Spira M, Mazaki-Tovi S, Schiff E, Sivan E, Achiron R. A novel sonographic scoring system for antenatal risk assessment of obstetric complications in suspected morbidly adherent placenta. J Ultrasound Med. 2015;34(4):561-7.

18. Rac MW, Dashe JS, Wells CE, Moschos E, McIntire DD, Twickler DM. Ultrasound predictors of placental invasion: the Placenta Accreta Index. Am J Obstet Gynecol 2015; 212(3):343.e1-7.

19. Shih JC, Jaraquemada JP, Su YN, Shyu MK, Lin $\mathrm{CH}$, Lin SY, et al. Role of three-dimensional power Doppler in the antenatal diagnosis of placenta accreta: Comparison with gray-scale and color Doppler techniques. Ultrasound Obstet Gynecol. 2009;33(2):193-203.

20. Hasegawa J, Matsuoka R, Ichizuka K, Mimura T, Sekizawa A, Farina A, et al Predisposing factors for massive hemorrhage during Cesarean section in patients with placenta previa. Ultrasound Obstet Gynecol. 2009;34(1):80-4.

21. Wong HS, Cheung YK, Zuccollo J, Tait J, Pringle JC. Evaluation of sono graphic diagnostic criteria for placenta accreta. J Clin Ultrasound. 2008; 36(9):5519.

22. Tovbin J, Melcer Y, Shor S, Pekar-zlotin M, Mendlovic S, Svirsky R, Maymon R. Prediction of morbidly adherent placenta using a scoring system. Ultrasound Obstet Gynecol. 2016;48(4):504-10.

23. Eller AG, Bennett MA, Sharshiner M, Masheter C, Soisson AP, Dodson M, Silver RM. Maternal morbidity in cases of placenta accreta managed by a 
multidisciplinary care team compared with standard obstetric care. Obstet Gynecol. 2011; 117(2):331-7.

24. Robinson BK, Grobman WA. Effectiveness of timing strategies for delivery of individuals with placenta previa and accreta. Obstet Gynecol. 2010;116(4):835-42.

25. Angstmann T, Gard G, Harrington T, Ward E, Thomson A, Giles W. Surgical management of placenta accreta: a cohort series and suggested approach. Am J Obstet Gynecol 2010;202(1):38.e19.

26. Finberg HJ, Williams JW. Placenta accreta: prospective sonographic diagnosis in patients with placenta previa and prior cesarean section. J Ultrasound Med. 1992;11(7):333-43.

27. Lerner JP, Deane S, Timor-Tritsch IE. Characterization of placenta accreta using transvaginal sonography and color Doppler imaging. Ultrasound Obstet Gynecol. 1995;5(3):198-201.

28. Twickler DM, Lucas MJ, Balis AB, Santos-Ramos $\mathrm{R}$, Martin L, Malone S, et al. Color flow mapping for myometrial invasion in women with a prior cesarean delivery. J Matern Fetal Med 2000; 9(6):330-5.

29. Guy GP, Peisner DB, Timor-Tritsch IE. Ultrasonographic evaluation of uteroplacental blood flow patterns of abnormally located and adherent placentas. Am J Obstet Gynecol. 1990;163(3):723-7.

30. Chou MM, Ho ESC, Lee YH. Prenatal diagnosis of placenta previa accreta by transabdominal color Doppler ultrasound. Ultrasound Obstet Gynecol. 2000;15(1):28-35.

31. Comstock $\mathrm{CH}$. The antenatal diagnosis of placental attachment disorders. Curr Opin Obstet Gynecol. 2011;23(2):117-122.

32. Finberg HJ, Williams JW. Placenta accreta: prospective sonographic diagnosis in patients with placenta previa and prior cesarean section. J Ultrasound Med. 1992;11(7):333-43.

33. Hamada S, Hasegawa J, Nakamura M, Matsuoka R, Ichizuka K, Sekizawa A, Okai T. Ultrasonographic findings of placenta lacunae and a lack of a clear zone in cases with placenta previa and normal placenta. Prenat Diagn. 2011; 31(11):1062-5.

Cite this article as: El-Gaber Ali AEA, Mohammad AAM, Khodry MM, Abdallah KM, Abbas AM.

Predictive values of ultrasound-based scoring system in morbidly adherent placenta for high risk group. Int J Reprod Contracept Obstet Gynecol 2018;7:442631. 